\title{
5
}

\section{Who Owns Our Tongue? English, Academic Life, and Subjectivity}

\author{
Kosuke Shimizu
}

\subsection{Introduction}

The issue of language as it relates to the disciplines of politics, International Relations (IR) and Asian Studies has received insufficient attention in contemporary academic circles, in part because of the uncritical assumption that language is an unloaded and transparent system of signs that merely conveys the meanings in the mind of the subject. Some scholars argue, however, that using English is a contradiction for the narratives of non-Western political theories and critical Asian Studies because, these critics suggest, English is an exclusively Western language. Nevertheless, the main language in contemporary academia is English, which accounts for a great deal of the publications, particularly in the case of the disciplines noted above. Even though the argument against the use of English in non-Western intellectual activities seems to be reasonable at first glance, a thorough investigation of the language and the disciplines will reveal some hidden and unquestioned assumptions underlying contemporary academic life, particularly relating to subjectivity. This article strives to criticize this immature acceptance of a naive equation of English with the West. Moreover, it argues that English is no longer a Western-owned language and that diversifying the ownership of English will direct us to a more democratic intersubjectivity. However, for this very reason, we must be prepared to accept a hitherto undreamt of grammatical transformation of English.

This grammatical transformation will have a substantial impact on academic circles because it relates to issues of translatability and subjectivity. Translation inevitably involves questions of grammar and pre-determined worldviews. For example, when one moves from the subject-centered ontology of Aristotle to the predicate-centered 
ontology of Nishida Kitaro (which one can interpret as an abstract form of a world order based on the China-centered tribute system), then the epistemological center of the world-the subject-acquires completely different, sometimes even opposite, forms (Shimizu, 2011). In order to reconcile differences of subjectivity and transcend the problem of incommensurability, contemporary intellectuals need to conduct a thorough investigation of the relationship between academic life and language.

The investigation in this chapter will concentrate on IR as a discipline because of the limited knowledge of the author, but this by no means implies that the argument developed here is inapplicable to other disciplines. Rather, I contend that any academic discipline must take into account the importance of language, particularly in an age of hegemonic domination by English. In order to clarify the points mentioned above, the chapter begins by introducing some arguments about IR and English mainly found in the literature of non-/post-Western International Relations theory (IRT). Second, I will strive to explain the meaning of English's hegemonic domination of IR by referring to Gramsci's theory of hegemony. Next, I will provide an introduction to the theory of World Englishes in order to comprehend the current state of language education and thereby acquire a clearer view of English. Fourth, I will focus on the issue of subjectivity and language by introducing Nishida's theory of the "place of nothingness" and the tribute-cum-trading system of China. I will argue that academic life has to prepare for different approaches towards subjectivity, and hence become an open-ended system of different discourses.

\subsection{Practicing IR in English}

People have long said that English is the world's lingua franca. It is true that the number of people speaking English-either as their first or second language- - has been increasing steadily worldwide. According to Kachru, there are three circles of English use. The inner circle includes countries where English functions as the first language, such as the UK, the US, Australia, Canada, and New Zealand. The outer circle includes countries such as India, Nigeria, and Singapore, where English is institutionalized. The expanding circle represents countries such as China, Japan, and Korea, where the diffusion of English has occurred relatively recently, although the social acceptability and social penetration of English is rapidly increasing (Kachru, 2006, p. 453). The fact is that users of English in the outer and expanding circles numerically overwhelm 
the users in the inner circle. Therefore, the common argument that English is shrinking because the number of English speakers is declining (Huntington, 1996) is misleading. Indeed, one to two billion people worldwide use English, and this means that $18 \%$ to $36 \%$ of the total global population was using English in 2005 (Kachru, 2006, p. 452). ${ }^{1}$

The situation is the same with IR. Indeed, English seems to be indispensable for understanding contemporary IR, as well as for publishing local knowledge internationally. Chris Brown, in his discussion of British IRT, succinctly summarizes this situation by stating that while Britain's quasi-hegemonic status has disappeared, the "English language remains the language of the discourse of IR" (2011, p. 310). This happened not because of the ease of teaching IR in English, or any recent re-acceptance of the English School by the world audience, but because of American dominance over the discipline (Hoffman, 1977). The English School should be referred to, in this context, as a partial counter-movement to Hoffman's idea of "IR as an American discipline" (Brown, 2011, p. 311), although this confrontation is occurring between two self-identified English-speaking groups.

However, the domination of English over the discipline is found even in the case of non-Western or post-Western IRT literature (Acharya \& Buzan, 2007; Chen, 2011; Shani, 2007, 2008; Shilliam, 2010) and one naturally expects the future to see more publications in English in this particular academic area.

Pedagogical practice is one of the most important dimensions of the relationship between IR scholarship and English. As has been observed for a long time, IR is taught mainly in English in the Anglophone world as a Western, or American, discipline. However, even elsewhere, English is gradually becoming the dominant language. In the Asian region, for example, English is becoming the language of IR education. This is caused partly by the lack of appropriate teaching materials for IR in local languages (Hadiwinata, 2009, p. 57), and partly by the gradually increasing recognition in scholarly publications of what "international" means to the concept of subjectivity, which is exclusively based on the assumption of individualistic and self-centered actors in world affairs rather than collective and group-oriented ones (Wæver, 1998, p. 721). How is IR presently taught in Asia? The teaching methods for IR in Asia vary according to region. With respect to Southeast Asia, Chong and Hamilton-Hart (2009) argue that IR course content is sometimes inclined towards certain schools of thought in the region, either because of the influence of national educational policies or because of the educational background of teachers. A good example of the 
former is Vietnam, where Marxism is treated as the central theory. In the case of the latter reason, realism is mainly taught in some countries in Southeast Asia because the teachers, who were trained in Western institutions, internalize the Western perception of the non-Western world that these countries have unstable regional political relations and insecure governments (Chong \& Hamilton-Hart, 2009, pp. 5-6). The latter reason is particularly important for the purpose of the present article. Consequently, the issue of classroom language becomes central in teaching IR to local students. Indeed, teaching is occasionally conducted in English elsewhere, such as in Thailand (Prasirtsuk, 2007, p. 98), while countries such as Indonesia and Malaysia use local language textbooks that are translations from English (Balakrishnan, 2009, p. 117; Hadiwinata, 2009, p. 57). Even in Japan-where it is common knowledge that IR has been taught mainly in the local language with locally written textbooks-teachers started teaching IR in English, using textbooks distributed by Western publishers.

In terms of research, it is worth mentioning that the two leading journals of Asian IR-The Pacific Review and International Relations of the Asia Pacific-are published in English (Chong \& Hamilton-Hart, 2009, p. 2). Further, we find more English-language journals in this field listed in the Social Science Citation Index-e.g. the Chinese Journal of International Relations, Korean Observer, and Asian Perspectives. The number of Asian scholars producing published works in English shows, in general, an increasing trend, although others do face difficulties, mainly because of the language barrier and heavy workload. In the case of the Japanese Association of International Relations (JAIR), about one hundred members out of roughly two thousand published their books in English, and over three hundred members published articles in English. One expects the number to increase even more if the rate of increase remains the same in the future (Inoguchi, 2007, p. 374). However, some argue that this is an exceptional case. Hadiwinata, for instance, contends that academics and researchers in Indonesia still suffer from a lack of quality research and publications that meet international standards, despite the encouraging development of IR as an academic subject receiving a growing appreciation in many universities (Hadiwinata, 2007, p. 57). The situation is essentially the same in other Asian regions. In China, despite the country's growing presence as a political power in the international arena, related to its successful economic development, scholars seem to be reluctant to reach an international scholarly audience. David Shambaugh contends, "Chinese scholars have little voice or impact on the international IR studies community" because, besides linguistic 
barriers, they make "no effort whatsoever to publish in English or other foreign language journals and newspapers abroad" (2011, p. 366). In addition, the international output of Chinese scholarship is so tightly controlled and regulated by the government that a relatively small handful of China's IR scholars have received government approval to attend international meetings (Shambaugh, 2011, p. 366).

In the case of Asian IR, English is certainly an impediment. Acharya and Buzan write:

For those having to work in English as a second or third language, they may feel like it is a barrier, both because of the additional work necessary to put one's thoughts into a foreign language and because of the high rejection rates in the leading English-language IR journals. (2007, p. 296)

These factors certainly keep those working in the "rest of the world" away from engaging in IR in English. This results in relatively low rates of attempts to publish one's writing in a foreign language. This phenomenon is, in a sense, international. The prevalent reluctance to publish one's work in English is not confined to Asia. Indeed, there are some reports that similar trends can be found in the case of IR in nonAnglophone European countries (Friedrich, 2004; Wæver, 1998).

Is English really an impediment for IR scholars in non-Anglophone regions? Should we give up any attempt to announce to a global audience that there are different, and in some cases more convincing, interpretations of IR in these regions? Although the number of scholars engaging in IR research and teaching in English in these areas is still limited, this engagement contains the possibility of an immense impact on IR literature itself when we further investigate the relationship between English and politics.

\subsection{What does it mean to study IR in English? Cultural hegemony}

As the development of IR is mainly confined to specific areas-the UK and the US-the widespread recognition that English is a lingua franca leads us to focus on the issue of politico-cultural hegemony in the Gramscian sense. Because IR as an academic subject is mainly organized in English, it is clear that academic work and publications cannot affect the international audience unless they are written in the dominant language or are translated into it. However, editorial boards and 
publishers determine and tightly control what is deemed to meet the "international standard," and proficiency and fluency in English are indispensable determinants in international publications and conferences. Scholars publishing articles and books in English receive large numbers of emails every day from companies providing translation and proofreading services.

The ascendance of English in the field of IR leads us to an argument of cultural hegemony, in the (Gramscian) sense that "the use of any language privileges a certain pattern of thought, a specific culture, and particular way of constructing truth" (Friedrich, 2004, p. 8). In other words, the achievement of worldwide recognition in the IR community requires a profound understanding of a certain pattern of thought inherited from a specific geographical area, of a specific cultural background and of the influence of the language on truth constructions. Therefore, to understand IR, we naturally feel the need to internalize not only the language structure but also its historical and cultural background. This, of course, shapes our language pattern and the logical arrangement of knowledge production. Thus, when we write our ideas in English, the arguments we make often result in subconsciously representing, or at least partially representing, the culture and history shared by Englishspeaking societies.

This leads us to suggest that there is indeed a hegemony of Anglophone IR theories-of the US in particular-in the contemporary academic discipline of IR.

This situation regarding the language and the hegemony of Anglophone IR stays the same if the current mutually reinforcing relationship remains. However, this narrative does not seem to be inevitable if we take into account the recent development of "World Englishes" theory in the study of second language acquisition. The term "World Englishes" here refers to an academic sub-field that accepts localized indigenous English as a legitimate language and encourages the diversification of English, ranging from dialect to creole and pidgin. This theory was initially developed in the late 1980s and the early 1990s, and now seems to have been increasingly accepted in the field of applied linguistics. The term "World Englishes" is often mistakenly assumed to be interchangeable with "World English," but the two terms have very different meanings. The latter refers to English as the lingua franca in business, diplomacy, and other forms of global activity, while the former refers to English in a variety of localized forms, including hybrids and creoles.

The arguments that support World Englishes theory inevitably involve focusing on the former British colonies, where English is still used on 
a regular basis. Theorists of World Englishes often concentrate on the power relationship between the former colonizers and the colonized. Thus, the arguments are highly political and some scholars working on this new development often cite postcolonial critiques in explaining the power relations embedded in language use (Dhillon, 2006).

From the beginning, as seen in Edward Said's Orientalism, postcolonial critique has been profoundly influenced by Gramsci's theory of hegemony, as well as Michel Foucault's use of "genealogy." By citing these philosophical works, Said dramatically revealed that the Western political powers constructed both the representation of the "Orient" and the identity of the "Occident" (Said, 1978). The critique of Orientalism intersects with the broad intellectual movements contesting the homogeneity and essentialism that Enlightenment humanist values were said to assume, and the wide-ranging acceptance of Said's Orientalism represents a manifestation of the crisis of Western humanism in both its Enlightenment and modernist forms. Said argues that, as a discourse of power, Orientalism constrained and shaped the ways in which the object of its vision, the non-Western other, was perceived and represented (Dhillon, 2006, p. 531). This critical project involved two distinct operations. The first was Foucault's re-visioning of Enlightenment science as that which generated a series of "othering" discourses and was thus deeply involved with the project of control. The second program involved revealing the supremacist implications of the Enlightenment idea of progress (Dhillon, 2006, pp. 531-532). This, in turn, transformed the intellectual field of Oriental Studies and Colonial Studies by pitching the discussion in a new way (Spivak, 1988). By bringing this theory into the discussion of language and IR, we inevitably become aware of the power relationship between the "self" and "other."

However, it is often said that Said's theory of Orientalism is based upon a perception that assumes a rigid dichotomy between the West and the Orient. His explanation, therefore, repeatedly renders an image of the world with inelastic boundaries and continuous confrontations over these boundaries. However, culture is not rigid or inflexible. Indeed, it often changes through encounters with other cultures and this generates the dynamism of cultural politics.

\subsection{World Englishes and the politics of language}

When we focus on the World Englishes literature more thoroughly, the dichotomy of the Occident and Orient becomes less sharp. One of the main architects of this theory is Braj Kachru, who, as I mentioned 
earlier, explains contemporary English by using three concentric circles, and his concept is the key to overcoming the dichotomy. In Kachru's three circles model, the inner circle consists of Anglophone countries like the UK, US, Australia, Canada, and New Zealand, where societies developed on the socio-linguistic foundation of English and English has been the first language. The outer circle refers to areas that have adopted English and used it as the first or second language because of their colonial past. These areas include India, Pakistan, Malaysia, the Philippines, and Singapore. The expanding circle involves Japan, China, Russia, and the non-Anglophone portion of the EU (Kachru et al., 2006).

These categories are closely related to four types of diaspora. Kachru and Smith (2008) write:

The first (diaspora) was to Ireland, Scotland and Wales, where local languages were supplanted by English; the second was to regions of North America, Australia, and New Zealand; the third to places such as India, Nigeria, Singapore, and the Philippines; and the fourth to countries such as China, Japan, Korea, Brazil, Germany, and Saudi Arabia, to name only a few in this category. (p. 5)

In this way, the inner circle was mainly constructed by the first and second diasporas, while the outer circle was constructed by the third and the expanding circle by the fourth. The existence of diasporas as mediators means that these three circles are in constant transformation. As different people intermingled with each other, so did the languages they used.

More interestingly, Kachru assigned different functions to each circle. He saw the inner circle as "norm-providing," which means that these countries provide what is regarded as Standard English. The outer circle is defined as the "norm-developing" zone, which develops its own local and endocentric variant of English norms. The third circle consists of "norm-dependent" countries that are seen to rely on the set of standards of English initially developed by the norm-providing countries (Kachru, 1992).

Although there has been a considerable amount of criticism of Kachru's three circles model (Higgins, 2003; Jenkins, 2003; Modiano, 2006; Pennycook, 2003; Seidlhofer, 2001), the model has played the vital role of questioning the existence of a uniform and inflexible English. Questioning the universality and uniformity of English leads us to the next question, namely, that of the diachronic evolution of language. Underlying this approach is the notion that any given language 
has never been and never will be static (Chew, 2010, p. 46). It is always in the process of transformation. The ever-changing nature of language, in turn, directs us to focus on the way in which a language is ceaselessly reformulated by socio-political forces.

The impact of the English language as an instrument of intellectual hegemony should not be overstated: it is possible to make good use of English without being over-conditioned by the linguistic medium. More than any other language, English has become neutralised with regard to the specific culture and/or patterns of thought in the mother country, so much so that one may even speculate whether, in addition to British and American English, a new branch of global and/or European English is in the making. (Friedrich, 2004, p. 9)

In a sense, English is probably one of the languages most influenced by the political and economic state of world affairs. Kachru, for instance, suggests that "English has not colonized us but we have colonized the language," quoting Philippine writer Francisco Sionil Jose, and argues that there is a "new revival, and a fresh awakening, about the use of a liberated English in the Philippines" (2006, p. 454).

In this sense, Kachru's statement that "the sun has already set on the Empire but does not set on the users of English" (2006, p. 452) certainly seems true, and this raises another question about the relationship between English and English-speaking societies in the norm-providing nation-states. Indeed, some argue that the separation of English as a language from English as a cultural representation is essential in teaching English. Asmah Haji Omar (1996) argues that English should be looked at "as an entity which can be separated from English culture," and she therefore advises those who are learning English "to learn English but not to ape the Western culture" (p. 532). If culture and language are distinguishable from each other, as Omar claims, then English is by no means the exclusive property of those living in the norm-providing areas and whose lives are embedded in English culture.

In this way, the theory of World Englishes provides contemporary English with a moment of disjuncture between culture and language, and this has major political implications for IR. First, the Westphalia system, which has long been regarded as a political arrangement based on the "Western" method of power distribution, can be revisited as the abstract form of an inter-state system because we can see that nationstates have been applied to and adopted by those areas that do not subscribe to the alleged "Western" political norms. Rather than perceive all 
nation-states, regardless of their geographical location, as standardized and homogenized in the way that the Westphalian norms prescribe, hybrid forms of nation and state are far more likely in reality. In fact, many writers from the outer circle, such as Salman Rushdie, Rohinton Mistry, Shashi Tharoor, Amitav Ghosh, and Arundhati Roy, employ hybrid forms of English and question the monolithic image of nationhood. Dissanayake contends:

These writers are seeking to gain entrance to their multifaceted subjectivities by "decolonizing" the English language and the sedimented consciousness that goes with it. Many of them regard the English language as the repressive instrument of the hegemonic colonial discourse. They wish to emancipate themselves from its clutches by probing deeper and deeper into their historical pasts, cultural heritages, and the intricacies of the present moment. Through these means, they seek to confront their protean selfhoods. What is interesting is that these writers are striving to accomplish this liberation through the very language that has in the past shackled them to what can be characterized as an ambiguous colonial legacy. (2006, p. 557)

In the stories of these writers, we can locate the counter-narratives of nation and the passionate endeavor to destabilize the political maneuvers through which imagined communities with essentialist identities become possible. This pluralized English here becomes the strategic means by which the given identity of the nation-state is questioned. We can say here that English is no longer the exclusive property of those residing in the core, but is owned by the entire population, who use it every day as a device for communication.

Second, if the theory of World Englishes not only transfers our focus onto a new awareness of the subjectivity of the periphery, it also questions the subjectivity of contemporary world affairs in general. As the above quotation reveals, the theory of World Englishes, in the age of postcoloniality, dismantles a fundamental notion. Identity is seen as neither rigid nor robust; rather, it is often protean and amalgam-like. This protean self often strategically takes an identity in one place and substitutes it with another identity in a different context.

These writers are constantly crossing and recrossing boundaries both topographical and linguistic so as to capture the complex dynamics of the present historical conjuncture and cultural moment. Some of them move back and forth between home and exile, at times 
interchanging their ontologies. They are exiled from home but at home in the language that over-determines the exilic experience, and their identities are shaped in the tensional interstices of two cultures. This liminality, in-betweenness, appears to be vital maker of postcolonial spaces. (Dissanayake, 2006, p. 558)

Those who hold different identities at different points in time and space move through and cross over the pre-set boundaries of cultures. They continuously generate the space of encounters, conflicts, and amalgams for various cultures and traditions. Therefore, cultures, like languages, undergo social construction and are subject to continuous transformation.

The idea of ever-transforming cultures and languages has an immense impact not only on the periphery of the concentric circles but also at the very core. In fact, harsh reactions have erupted from the core against the idea of transformative cultures and languages. Samuel Huntington, for instance, argues that the English spoken in certain areas is "unintelligible" (1996, p. 62). Quirk calls for "universally recognized standards" of English so that the language retains its "reliability" (2003, pp. 13-14). This reaction also involves economic interests. Kachru (2006) rightly talks about "English as a commodity, with immense value in the international language market." Those who "own" the commodity demand the right to "safeguard it and preserve it in terms of pounds and dollars" (Kachru, 2006, p. 463). In such cases, ideas about "standard" and "normative" English are a part of the production of economic profit.

The problem here is that safeguarding the boundaries of English conflicts with the hybridity of English that we can see around the world. What we should focus more on is instead creativity, which the pluralization of English brings into being; this focus in turn forces us to reorient our perception towards "what constitutes a harmonious, cohesive, integrated, and motivated speech community" (Kachru, 2006, p. 463).

\subsection{From confrontation to relationality}

The controversy over World Englishes is characterized by the rigidity of the contestants, both those who strive to protect the privileged status of norm-providing cultures and those who shake the pre-given structure of domination through the means of language as explained above. Both sides have their own justifications and rationalizations. Those trying to protect the dominant regime of English argue that the concept of varieties of English leads to unintelligibility and incommensurability 
among the users, while those attempting to portray the hybrid nature of identities through their defense of localized English contend that the idea of varieties of English is essential in constituting democracy in the newly emerging cosmopolitan culture.

What permeates both positions, however, is a subjectivity constructed prior to the confrontational encounter between the two sides of the World Englishes dispute, and the subjectivity that each side focuses on is presumably constructed by socio-political factors and elements elsewhere. Some may argue against the statement that the hybrid forms of identities are not set a priori, in the sense that their subjectivities are constituted through the practice of crossing over cultural boundaries. This is correct, and this is precisely the reason why I contend that their identities are pre-set. Their subjectivities are assumed to exist before the dispute. What is missing in this argument is the awareness that subjectivity is constituted and discovered through the World Englishes dispute over who owns the language. In other words, the presumed dialectical relationship between the core and periphery misses the point of the construction of subjectivity through the investigation of relationality. It is not local history, heritage, and the experience of crossing over boundaries that perform an essential role in the construction of subjectivity. Rather, one can say that those engaged in the dispute in search of these elements discover these subjectivities, which account for their peculiar identities that then must be distinguished from the "other."

In this sense, the concept of World Englishes clarifies a system of relationality, which includes the subjectivity of the disputants in the World Englishes dispute, where the emergence of relationships constructs the subjects. Therefore, the important issues here are how relationships shape and engender the subject, and how this process of subjectivity production ensures the emergence of an inclusive public domain in world affairs.

The idea of relationality, which constitutes subjectivity, is relatively visible and is often understood as common sense in the peripheries of the contemporary hegemony. Perhaps one of the archetypal examples in this context is Nishida Kitaro's philosophical concept of the "place of nothingness." Nishida, one of the most prominent Japanese philosophers, claimed that individuals do not exist prior to experience, but, rather, experiences construct individuals (Nishida, 1947, p. 4). Thus, individual identity relies entirely on its experiences. In society, the experiences that produce individual identities are, by definition, social, and therefore relational. This means that the relationality of subjects becomes the central focus of inquiry into socio-politics. 
How, then, do socio-political relations constitute the subject? Here, probably, it is important to distinguish self-image from self-identity. Shih (2012) contends that self-identity is about drawing boundaries between the self and others in order to distinguish between them (p. 25). Identity construction is therefore intended to discover something different from the character of everyone else. This becomes a cause of violence, whether physical or discursive. In sum, identity making is a practice of violent "othering." Imamura (2008) goes even further, arguing that violence is caused by what he calls the "original division," and this original division resides in the use of the " $\mathrm{I}$ " that draws a boundary between "I" and "You." This original division is inherently violent in the sense that it engenders a distance between entities, and this distance is stabilized and institutionalized through the universalization of specific subjects through a standardized vocabulary (Imamura, 2008, p. 73).

Image, by contrast, is about the "evaluation" of others. In this context, the subject "performs in accordance with a certain consensually agreed upon role, explicitly as well as implicitly, between one and other who presumably evaluate" (Shih, 2012, pp. 25-26). Because others are the mirror that reflects the image of the subject, the latter is inevitably involved in relationships with others. While identity is rigid in the sense that it is presumably an a priori construction existing before the formation of relationships, image is, by definition, context-sensitive and, therefore, flexible with respect to the relationship (Shih, 2012, p. 26).

In this system of relationality, the subject is always changing and so is the system. Thus, "order" means the continuous transformation of subjectivity and relationality. There is no pre-given order or norms, but instead an interminable flow of relations. A reification of this system in IR is China's tributary trading system.

Hamashita (1990) defines the tributary system as an always-changing system based on trade relations, which is inclusive of different elements. This inclusivity emanated from the core of the system, which actually had a relatively weak centripetal force (Hamashita, 1990, pp. 32-33). All relationships among member countries were bilateral rather than multilateral, so that no member faced exclusion as a result of the violation of universal norms and regulations, simply because there was no such thing. Rather, all bilateral relationships were dealt with on a case-by-case basis (Shih, 2013) and this resulted in constant systemic transformations. Since this system was not constructed on a foundation of strong centripetal power, unlike the hegemony generally familiar to the contemporary IR audience, all members in the tribute system were allowed to have their own "centres" (Hamashita, 2003, p. 20). 
What becomes the central theme in comprehending this complex system is the "periphery," as in the case of World Englishes. By focusing on the periphery of the system, it becomes clear that "inclusiveness," "mediation," and "differentiation" are the essential characteristics of a tribute structure of multiple centers (Hamashita, 1994, p. 3). According to Hamashita, what characterized the indispensable functions that those peripheries performed in the tributary system was the spontaneous relationship among ports. The intricate network was composed of a web of maritime trading routes between the center and the peripheries, and between one periphery and another, in each case on a bilateral basis. Unlike the general perception that prevails in the contemporary geographical understanding of oceans, which sees them as obstacles and impediments to trading, the perception presented by Hamashita (2003) is one in which the oceans shaped a public sphere in Asia before the sudden arrival of Western modernity and civilization.

The region's socio-political and socio-economic dynamism was mainly generated at the peripheral areas instead of at the center. This is because there were multiple centers in the system; the entire structure of tribute-cum-trading was constructed on the premise of multiple circles overlapping with the major system (of concentric circles) and with each other. The peripheries thus occurred at the intersection of the various circles, and were characterized by mixed cultures.

The above analysis reveals the blurred core of the tribute system, and resembles the concept of diffuse centers of World Englishes. The World Englishes theory suggests that the dynamism of English is mainly generated in the "outer circle." Similarly, the primary functioning part of the tribute-cum-trading system was the periphery. This in turn reveals the inflexible perception of the hegemony of contemporary IR, and raises serious doubts about the unquestioned superiority of the subjectivity residing at the core of the system of IR.

How could we theorize the blurred subjectivity evident in both the theory of World Englishes and the tribute-cum-trading system? This vague image of the subject is completely opposed to that assumed by traditional Western philosophy-an autonomous and sovereign subject with strictly demarcated boundaries. In order to find a possible answer to this question, we have to go back to what Nishida Kitaro calls the "place of nothingness." Nishida argues that the subject is not autonomous or independent. The subject in the ordinary sense is always to open to society and depends on relationality for its construction. However, at the same time, this subject encompasses all the relationality that appears to the subject. Therefore, the subject is 
constructed by interactions with others while also providing the space for such interactions. This space is, in a sense, not a subject, however, because it only accepts and permits these interactions to take place. Therefore, it is a place (Nishida, 1949).

This is, in a sense, a double subjectivity, which consists of a constructed and an encompassing subject. These two are contradictory, but are integrated simultaneously. This contradiction is absolute rather than relative, because this contradiction involves the self's opposition to itself. There is nothing in this place prior to the interactions, and thus Nishida sometimes describes it as the "place of absolute nothingness," which is in sharp contrast to "relative nothingness," which is indeed antonymous to "being." In this sense, a place of nothingness is based on the concept of the absolute nothingness, and in fact Nishida later used a different concept to refer to the same idea, namely, "absolute contradictory self-identity" (Nishida, 1965).

It is possible to say that Nishida's concept of the "place of nothingness" is the key to understanding the political meaning of World Englishes and the tribute system of China. Both are inclusive towards others and have a blurred center. Nevertheless, they function as systems with coherence and continuity. They transform themselves into something new in a continuous manner. In this sense, using Englishes as a communicative device for comprehending contemporary world affairs is equivalent to saying that IR is a place that is inclusive towards different narratives and the discourses of others.

Introducing the concept of the "place of nothingness" and the tribute system of China into our intellectual activities is more of a thought experiment than the provision of a concrete policy program. It is suggestive, however, in considering the future paradigm of research methodology. In order to transform IR into a more diverse and democratic discipline, we have to ready ourselves for the forthcoming changes that will presumably take place at the peripheries. Rather than turn down arguments and theories of non-Western traditions mainly because of their "imperfect" English quality or logical inconsistency, we have to focus more on elements, whether intentional or coincidental, generated by new and unfamiliar forms of representation. IR will otherwise become one of those means of unification and standardization at the world scale that, according to Hannah Arendt, are a typical feature of the disappearance of the public and totalitarianism. Thus, we can conclude here that it is not others who need to be transformed into something new, but those who are working on contemporary world affairs. 


\subsection{Conclusion}

In this chapter, I have tried to explain how language easily becomes a device for the totalizing and unifying power of modern politics, while nevertheless also containing the potential for transformation and diversification of our perception of the contemporary world. I also strived to clarify that the transformative elements often appear not in the center of the world, but in the relationship with peripheries. It is in this relationship between the core and peripheries that diversification processes initially take place. The diversification of perception is of particular importance in the context of contemporary multiculturality in the region in the sense that it presumably creates a more democratic sphere for intersubjectivity. Without the democratic intersubjective space, conflicts and confrontations in the substantive world would seem to be more likely.

However, this diversification is by no means an easy task, because language is often associated with and controlled by nation-states with established subjectivities. When we focus on Japanese, for instance, it automatically gives us the impression that we are to deal with Japan as a nation-state, Japanese culture as maintained by Japanese nationals, and Japanese history as something continuous and linear. This is the conceptual power of the nation-state that severely controls our intellectual lives. In this sense, conducting critical investigations into languageand subsequent critical analysis of subjectivity-must inevitably involve a critical inquiry specifically into the concept of the nation-state. Therefore, the next questions to address in this context include the following: Why does the concept of the nation-state hold such a strong power over human thinking? Why is it extremely difficult to think of the world without the concept of the nation-state? What sort of world could we imagine if we consciously avoided the use of the concept? These questions obviously pose a serious challenge to researchers, but I firmly believe that they are worth trying to answer.

\section{Note}

1. The population estimates are from 2004.

\section{References}

Acharya, A. \& Buzan, B. (2007). Why is there no non-Western international relations theory? An introduction. International Relations of the Asia-Pacific, 7(3), 287-312.

Balakrishnan, K. S. (2009). International relations in Malaysia: Theories, history, memory, perception and context. International Relations of the Asia-Pacific, 9(1), 107-130. 
Brown, C. (2011). Development of international relations theory in the UK: Traditions, contemporary perspectives, and trajectories. International Relations of the Asia-Pacific, 11(2), 309-330.

Chen, C. C. (2011). The absence of non-Western IR theory in Asia reconsidered. International Relations of the Asia-Pacific, 11(1), 1-23.

Chew, P. G. L. (2010). From chaos to order: Language change, lingua francas and world Englishes. In M. Saxena, \& T. Omoniyi (Eds), Contending with globalization in world Englishes (pp. 45-71). Bristol: Multilingual Matters.

Chong, A. \& Hamilton-Hart, N. (2009). Teaching international relations in Southeast Asia: Historical memory, academic context, and politics-An introduction. International Relations of the Asia-Pacific, 9(1), 1-18.

Dhillon, P. (2006). Colonial/postcolonial critique: The challenge from world Englishes. In B. B. Kachru, Y. Kachru, \& C. L. Nelson (Eds), The handbook of world Englishes (pp. 529-544). Oxford: Blackwell.

Dissanayake, W. (2006). Cultural studies and discursive construction of world Englishes. In B. B. Kachru, Y. Kachru, \& C. L. Nelson (Eds), The handbook of world Englishes (pp. 545-566). Oxford: Blackwell.

Friedrich, J. (2004). European approaches to international relations theory: A house with many mansions. London: Routledge.

Hadiwinata, B. S. (2009). International relations in Indonesia: Historical legacy, political intrusion, and commercialization International Relations of the AsiaPacific, 9(1), 55-81.

Hamashita, T. (1990). Kindai chugoku no kokusaiteki keiki [The international turning point of modern China]. Tokyo: Tokyo University Press.

Hamashita, T. (1994). Shuhenkarano ajiashi [The Asian history from periphery]. In Y. Mizoguchi, T. Hamashita, N. Hiraishi, \& H. Miyazaki (Eds), Shuhenkarano rekishi [The history from periphery] (pp. 1-14). Tokyo: Tokyo University Press.

Hamashita, T. (2003). Tribute and treaties: Maritime Asia and treaty port networks in the era of negotiation, 1880-1900. In G. Arrighi, T. Hamashita, \& M. Selden (Eds), The resurgence of East Asia: 500, 150 and 50 year perspective (pp. 1-16). London: Routledge.

Higgins, C. (2003). Ownership of English in the outer circle: An alternative to the NS-NNS dichotomy. TESOL Quarterly, 37(4), 615-644.

Hoffman, S. (1977). An American social science: International relations. Daedalus, 106(3), 41-60.

Huntington, S. P. (1996). The clash of civilizations and the remaking of world order. New York: Simon and Schuster.

Imamura, H. (2008). Boryokuizen no chikara, boryoku no kongen [The power prior to violence, the origin of violence]. In T. Tani (Ed.), Boryoku to ningen sonzai [Violence and human existence] (pp. 70-86). Tokyo: Chikumashobo.

Inoguchi, T. (2007). Are there any theories of international relations in Japan? International Relations of the Asia-Pacific, 7(3), 369-390.

Jenkins, J. (2003). World Englishes: A resource book for students. London: Routledge.

Kachru, B. B. (1992), The other tongue: English across cultures. Urabana: University of Illinois Press.

Kachru, B. B. (2006). World Englishes and culture wars. In B. B. Kachru, Y. Kachru, \& C. L. Nelson (Eds), The handbook of world Englishes (pp. 446-471). Oxford: Blackwell.

Kachru, B. B., Kachru, Y., \& Nelson, C. L. (Eds) (2006). The handbook of world Englishes. Oxford: Blackwell. 
Kachru, Y., \& Smith, L. E. (Eds) (2008). Cultures, contexts and world Englishes. New York: Routledge.

Modiano, M. (2006). Euro-Englishes. In B. B. Kachru, Y. Kachru, \& C. L. Nelson (Eds), The handbook of world Englishes (pp. 223-239). Oxford: Blackwell.

Nishida, K. (1947). Zen no Kenkyu [An inquiry into the good]. In Nishida Kitaro zenshu [Collected works of Nishida Kitaro] (Vol. 1, pp. 3-200). Tokyo: Iwanami.

Nishida, K. (1949). Baho [The place]. In Nishida Kitaro zenshu [Collected works of Nishida Kitaro] (Vol. 4, pp. 208-289). Tokyo: Iwanami.

Nishida, K. (1965). Zettai mujunteki jiko doitsu [The absolute contradictory selfidentity]. In Nishida Kitaro zenshu [Collected works of Nishida Kitaro] (Vol. 4, pp. 147-222). Tokyo: Iwanami.

Omar, A. H. (1996). Imperial English in Malaysia. In J. A. Fishman, A. W. Conrad, \& A. Rubal-Lopez (Eds), Post-Imperial English: Status change in former British and American colonies 1940-1990 (pp. 513-533). Berlin: Mouton de Gruyter.

Pennycook, A. (2003). Global Englishes, rip slyme, and performativity. Journal of Sociolinguistics, 7(4), 513-515.

Prasirtsuk, K. (2007). Teaching international relations in Thailand: Status and prospects. International Relations of the Asia-Pacific, 9(1), 83-105.

Quirk, R. (2003). From Latin to English. The Use of English, 55(1), 7-15.

Said, E. (1978). Orientalism, New York: Vintage.

Seidlhofer, B. (2001). Closing a conceptual gap: The case for a description of English as a lingua franca. International Journal of Applied Linguistics, 11(2), 133-156.

Shambaugh, D. (2011). International relations studies in China: History, trends, and prospects. International Relations of the Asia-Pacific, 11(3), 339-372.

Shani, G. (2007). "Provincializing" critical theory: Islam, Sikhism and international relations theory. Cambridge Review of International Affairs, 20, 417-433.

Shani, G. (2008). Towards a post-Western IR: The Umma, Khalsa Panth, and critical international relations theory. International Studies Review, 10, 722-734.

Shih, C. Y. (2012). Civilization, nation and modernity in East Asia. London: Routledge.

Shih, C. Y. (2013, March). Balance of relationships: A Confucian route for international relations system. Paper presented at the International Symposium on English School. Ritsumeikan University, Kyoto.

Shilliam, R. (2010). International relations and non-Western thought: Imperialism, colonialism and investigations of global modernity. London: Routledge.

Shimizu, K. (2011). Nishida Kitaro and Japan's inter-war foreign policy: War involvement and culturalist political discourse. International Relations of the Asia-Pacific, 11(1), 157-183.

Spivak, G. C. (1988). Can the subaltern speak? In C. Nelson \& L. Grossberg (Eds), Marxism and the interpretation of culture (pp. 271-313). Urbana: University of Illinois Press.

Wæver, O. (1998). Sociology of a not so international discipline: American and European developments in international relations. International Organization, 52(4), 687-727.

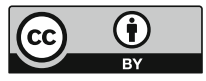

Except where otherwise noted, this work is licensed under a Creative Commons Attribution 3.0 Unported License. To view a copy of this license, visit http://creativecommons.org/licenses/by/3.0/ 